\title{
Comunicación

\section{Datos para una radiografía de los estudios brasileños de recepción}

\author{
ANA CAROLINA D. ESCOSTEGUY ${ }^{1}$
}

Este artículo presenta algunos resultados parciales obtenidos mediante un análisis metodológico de disertaciones y tesis, implementada en la ejecución del proyecto "Os Estudos culturais e a problemática da recepção: a categoria gênero em debate" (CNPq/FAPERGS ). ${ }^{2}$ En esta etapa, los datos son sólo descritos, sirviendo de preludio para una radiografía de los estudios brasileños de recepción, realizados en el ámbito académico, en la decada de los noventa.

Palabras clave: estudios de recepción; metodologías de investigación; género.
This article presents some partial results obtained through a methodological analysis of thesis and dissertations, implemented in the execution of the proyect "Os Estudos culturais e a problemática da recepcao: a categoria genero em debate” (CNPOQ/FAPERGS)2. At this stage, the data are just described and serve as a prelude for an $x$-ray of the Brazilian studies of reception, carried out within the academic environment during the decade of the 90's.

Key words: Reception studies, methodologies of investigation, gender.

1 Profesora del Programa de Posgrado en Comunicación de la Pontificia Universidad Católica del Río Grande del Sur; investigadora del Consejo Nacional de Desenvolvimiento Científico y Tecnológico/ CNPq. Traducción del portugués al español por la autora.

Correo electrónico: carolad@pucrs.br.

2 Actuaron como alumnos integrados al proyecto: Mariana Pires (BIC/CNPq), Pedro Henrique Reis (BIC/CNPq) y Cristina Vanuzzi (BIC/FAPERGS). Todos desarrollaron actividades que contribuyeron para este artículo, quedando a cargo de Mariana Pires el levantamiento de los datos finales y la ejecución de las tablas presentadas. Contribución de Barabara Nassif (BIC/CNPq) en la ejecución de los gráficos. 
En la actual etapa de la investigación "Os estudos culturais e a problemática da recepção: a categoria do gênero em debate" (CNPq e FAPERGS), se busca ordenar un levantamiento de las características y metodologías de los estudios brasileños de recepción, realizados en el ámbito académico, en la década de los noventa. Aunque la hipótesis que funda nuestra investigación se circunscribe al modo por el cual es incorporada la categoría de género en los estudios de recepción, afirmando que el uso de tal término no significa un cambio de paradigma analítico, como tal vez fuera esperado por una perspectiva feminista, este artículo trata apenas de enlistar algunos de los resultados que se pueden presentar en este momento. Por lo tanto, estas anotaciones no tienen carácter conclusivo, son parciales y sujetas a alteraciones.

El corpus de disertaciones y tesis que enfocan de modo central el público receptor, realizadas en el período de 1990 a 1999, en programas de posgrado en comunicación, en el contexto nacional, fue compuesto a través de la consulta de los dos volúmenes de Teses e dissertações em comunicação no Brasil (1992-1996) e (1997-1999) -resumos, organizados por Ida Regina Stumpf y Sérgio Capparelli, y principalmente del volumen Estudos brasileiros de recepção- a produção adacêmica da década de 90, organizado por Nilda Jacks. ${ }^{3}$ Después de la elaboración de un listado de tales investigaciones, se procedió al estudio y análisis del corpus referido. ${ }^{4}$ Mediante la lectura integral de esos estudios fueron eliminados aquéllos que, aunque utilizaban la palabra o referencias al término audiencia, público, recepción y/o mediación en sus resúmenes, no enfocaban propiamente esa problemática. El número total de investigaciones encontradas que tratan la audiencia como foco central fue de 50.

Entiéndase por abordaje de la audiencia, la visión que la investigación expresa sobre el público receptor. Dada la extensión conceptual de esa área, proponemos la clasificación en abordaje socio-cultural, comportamental y otros (Gráfico 1). La primera abarca una visión amplia y compleja del proceso de consumo de los productos mediáticos donde son consideradas múltiples relaciones sociales y culturales. Com-

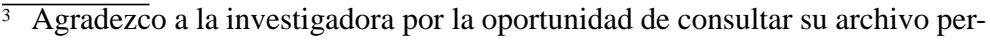
sonal de disertaciones y tesis.

4 El análisis de investigaciones siguió algunas premisas propuestas por Lopes, 1990.
} 


\section{GRÁFICO 1}

ABORDAJE DE LA AUDIENCIA

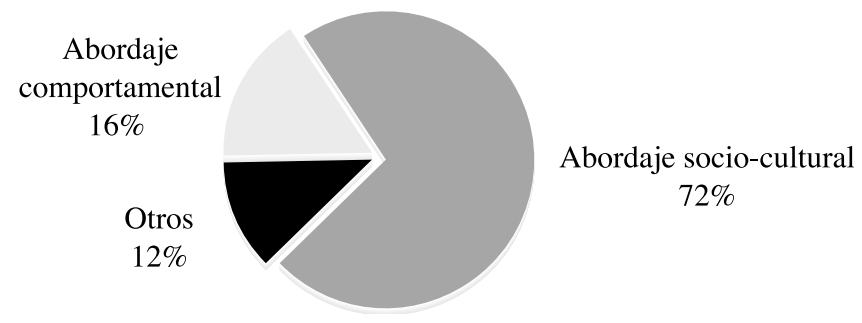

Base: 50 (No. de investigaciones analizadas)

prende el estudio del fenómeno de recepción en sí mismo y se investiga su inserción social y cultural. Es en esa concepción donde, desde nuestro punto de vista, adquiere propiedad la utilización del término recepción. El abordaje comportamental es utilizado para reunir investigaciones que estudian los diferentes impactos comportamentales derivados de los media, esto es, el producto mediático es considerado un estímulo que provoca diferentes reacciones en los públicos. Ahí se encuentran aquellos estudios que ven los media como formadores de opinión, estudios de efectos, de efectos cognoscitivos, usos y gratificaciones y otras investigaciones de carácter psicológico que reducen el producto mediático al juicio del público. En la categoría otros, reunimos investigaciones de orientación diversa, por ejemplo, el receptor idealizado bajo el punto de vista del emisor y la revisión y descripción de otras teorías de la recepción.

La intención es observar la relación entre la autoría de las investigaciones, de acuerdo con el género (Gráfico 2), y los estudios de recepción. ${ }^{5}$ Este criterio fue establecido teniendo en cuenta que, en el contexto anglo-americano, hay un fuerte debate sobre las contribuciones del feminismo para los estudios de recepción. Aunque los investigadores de-

5 A partir de aquí observamos apenas el subconjunto de investigaciones clasificadas dentro del abordaje socio-cultural, por considerarlas, de hecho, aquéllas que se configuran como estudios de recepción. 


\section{GRÁFICO 2}

AUTORÍA DE LOS ESTUDIOS DE RECEPCIÓN

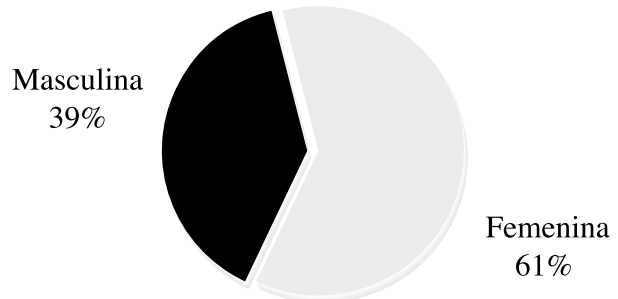

Base: 36 (No. de investigaciones analizadas dentro del abordaje socio-cultural)

nominados feministas no sean exclusivamente mujeres, hay una fuerte presencia de las mismas en ese ámbito.

Se observa la relación entre el abordaje socio-cultural y la presencia de un bloque de autores, sobre todo latinoamericanos, que fundamentan tal visión de público receptor. Los autores son Jesús MartínBarbero, Néstor García Canclini, Guillermo Orozco (Gráfico 3). Existen investigaciones que combinan esos mismos autores, así como algunas utilizan otras referencias. ${ }^{6}$

El propósito es observar el desarrollo de la investigación de recepción a lo largo de la década de los noventa, y comprobar si hubo o no un incremento de estudios sobre la temática. En la medida en que la fuerte incidencia de la reflexión de Jesús Martín-Barbero como referencial teórico de esas investigaciones, se buscó también si la traducción de su obra mayor, Dos meios às mediações, contribuyó a aumentar el uso de sus formulaciones de los estudios de recepción después de 1997 (Gráfico 4).

La propuesta más amplia de los estudios de recepción coincide con el propósito de observar cómo la sociedad se expresa en los distintos media. A pesar de enfocar de forma preferencial el momento de la recepción, éste no debe ser visto en sí mismo, sino como mediación para comprender la totalidad del proceso de comunicación. Así mismo, las

6 Entre los autores incluidos en esta categoria están: Michel de Certeau, Mikhail Bakthin, Paulo Freire, Pierre Bourdieu. 


\section{GRÁFICO 3}

PRINCIPALES AUTORES UTILIZADOS EN LOS ESTUDIOS DE RECEPCIÓN

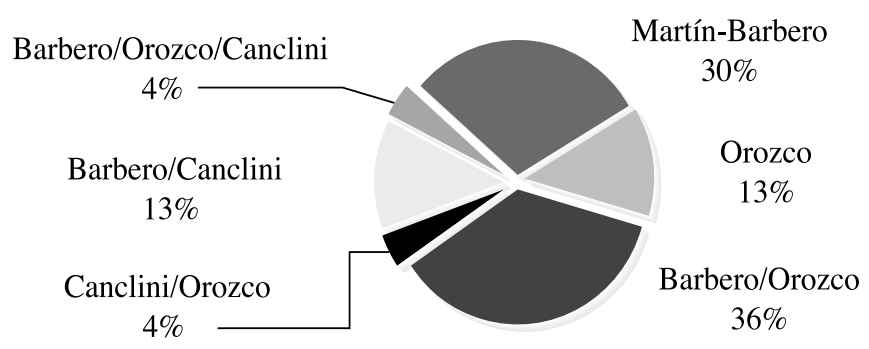

Base: 23 (No. de investigaciones analizadas dentro del abordaje socio-cultural que utilizan esos autores, las 13 restantes trabajan a partir de otros autores)

\section{GRÁFICO 4 \\ AÑO DE REALIZACIÓN DEL ESTUDIO DE RECEPCIÓN}

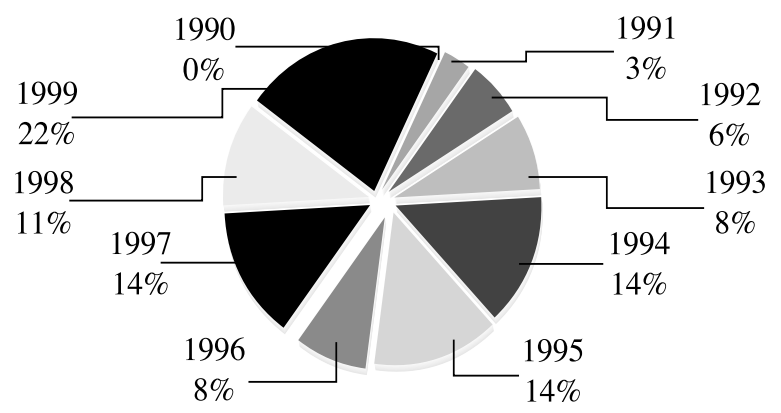

Base: 36 (No. de investigaciones analizadas dentro del abordaje socio-cultural)

investigaciones estudiadas seleccionan un medio o una forma de comunicación para análisis. Por esta razón, esta clasificación identifica la televisión, ${ }^{7}$ la radio, los medios impresos, el cine, la comunicación alternativa (por ejemplo, radios comunitarias) y los medios en general

7 El enfoque puede ser la telenovela, la publicidad televisiva, el dibujo animado, el cine en la televisión, entre otros. 


\section{GRÁFICO 5 \\ MEDIO DE COMUNICACIÓN ESTUDIADO}

Medios de comunicación en general

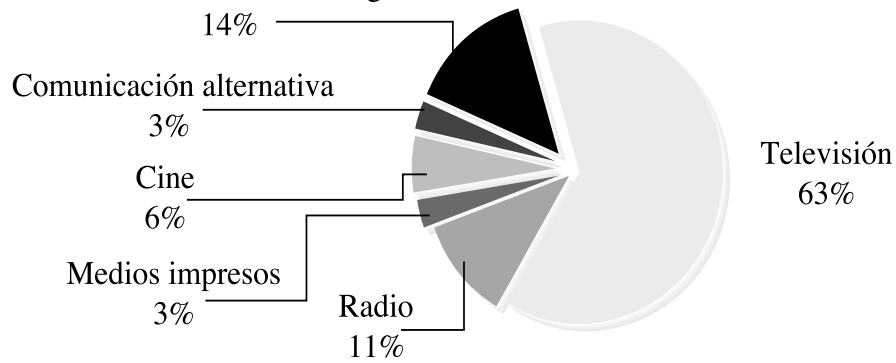

Base: 36 (No. de investigaciones analizadas dentro del abordaje socio-cultural)

combinados con otras formas de comunicación (entre ellas, la canción de consumo y cartillas de la Iglesia) (Gráfico 5).

Se clasifican en esta subdivisión las investigaciones según su naturaleza y objeto de investigación; esto es, cuando prioritariamente involucran la existencia del objeto empírico o evidencias concretas y cuando destacan objeto y cuestiones de carácter teórico ${ }^{8}$ (Gráfico 6).

Se entiende que los estudios de recepción pueden tener como fuentes primarias, ${ }^{9}$ personas, media (mensajes de medios electrónicos y/o impresos) y obras, siendo que los subconjuntos de personas y media se configuran en investigación empírica y el tercer grupo compone la investigación teórica (Gráfico 7).

Se observa, en esta clasificación, la fuente primaria preponderante; esto es, en algunos casos hay combinación, por ejemplo, de personas y media, pero los objetivos de la investigación, hipótesis y resultados destacan apenas uno de ellos. Se observa en este criterio de clasificación si

$\overline{8}$ Dos estudios insertos en esa categoría presentan investigación de campo. Uno de ellos se caracteriza como fundamentalmente investigación teórica, pero también se fundamenta en una estrategia etnográfica. La otra se utiliza de entrevista semi-estructurada colectando datos cualitativos y cuantitativos.

9 Se adopta la definición de Booth, Colomb y Williams (2000:92): "São os elementos sobre os quais você está escrevendo diretamente, as 'matérias-primas' de sua pesquisa. Em áreas que estudam autores ou documentos, os textos sobre os quais você escreve são fontes primárias". 


\section{GRÁFICO 6}

TIPO DE INVESTIGACIÓN

Investigación teórica $8 \%$

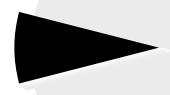

Investigación empírica

$92 \%$

Base: 36 (No. de investigaciones analizadas dentro del abordaje socio-cultural)

\section{GRÁFICO 7 \\ FUENTES CONSULTADAS}

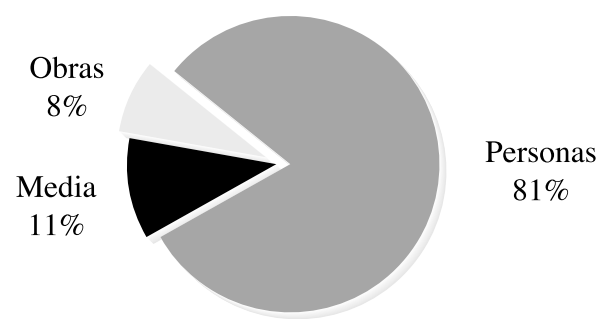

Base: 36 (No. de investigaciones analizadas dentro del abordaje socio-cultural)

la investigación trabajó con todas las unidades del universo de investigación (comunidad total) o si recolectó datos apenas de una parte del todo (muestra definida). En la tercera categoría (muestra sin especificación) se encuentran las investigaciones que realizaron investigación de campo, o sea, tienen muestra, pero no especificaron en el relato la composición de las mismas (Gráfico 8).

Este criterio de clasificación fue utilizado teniendo en cuenta uno de los objetivos de la investigación de observar cómo las relaciones 
del género eran tratadas por los estudios de recepción. ${ }^{10}$ Así, de aquellas investigaciones que se valieron de muestra, se identifica la composición de la misma por género. Las categorías de la muestra son: femenino o masculino; ambos géneros en un rubro o predominio, ya sea masculino o femenino (Gráfico 9).

En el gráfico 10 se observan diferentes técnicas de investigación, para recolectar evidencias o información para la investigación. Así, tenemos la entrevista, ${ }^{11}$ la historia de vida, ${ }^{12}$ la combinación de técnicas, ${ }^{13}$ los

$\overline{10}$ Dada la amplitud del campo de los estudios de género, el recorte adoptado en la investigación asocia el tema a las particularidades referentes a las mujeres. A partir de la incorporación de esa categoría en la investigación empírica y cualitativa de recepción, se identifica un aspecto singular en el desarrollo de los estudios culturales latinoamericanos en comparación con la tradición de los estudios culturales que se desarrollaron a partir del Centre for Contemporary Cultural Studies, fundado en Birmigham, en 1964.

${ }^{11}$ Es una técnica que implica la interacción entre investigador e informante, supone una conversación entre informante e investigador, pero es una "conversación con propósitos"; es una comunicación interpersonal orientada a la obtención de información sobre un objeto definido; el tema, el enfoque o el acontecimiento es elegido por el investigador; por eso es él quien dirige la entrevista. La entrevista puede seguir un camino previamente establecido u operar aparentemente sin mapa, pero deberá desarrollarse conforme alguna sistematización del investigador. Por esa razón, por más que se busque dejar al 'narrador' libre, el investigador tendrá una posición dominante porque desde el inicio de la colecta quien comanda la actividad es el investigador, pues son sus intereses los que determinan la obtención del relato. Los tipos considerados en esta categoría son: semiestructurada; focalizada o temática; no-directiva, libre o a profundidad. Las denominaciones varían según el autor utilizado para fundamentarlas.

12 Siguiendo la orientación de Maria Isaura Pereira de Queiroz (1991), la historia de vida se define como el relato de un informante sobre su existencia en el tiempo, tratando de reconstruir los acontecimientos que vivenció y transmitir su experiencia. Está compuesta a través de una serie de entrevistas donde la interferencia del investigador debe ser mínima.

13 Incluye el uso de entrevistas, cuestionario y observación directa participante o no participante. Por esa razón están en esa categoría los estudios de caso. También aquí está incluida la etnografía. Ésta incluye la descripción de eventos que ocurrieron en la vida de un grupo y la interpretación del significado de tales eventos para la cultura del grupo estudiado. La observación es el fundamento de la investigación etnográfica, pues es necesario el contacto intenso y prolongado con el grupo estudiado (Godoy, 1995). Aunque existan controver- 


\section{GRÁFICO 8}

PORCENTAJES GENERALES DE LOS DATOS

Comunidad total

$3 \%$

Muestra sin especificación

$14 \%$

Muestra

$83 \%$

Base: 29 (No. de investigaciones analizadas dentro del abordaje socio-cultural, de naturaleza empírica y con fuente primaria compuesta por personas)

\section{GRÁFICO 9 \\ COMPOSICIÓN DE LA MUESTRA SEGÚN EL GÉNERO}

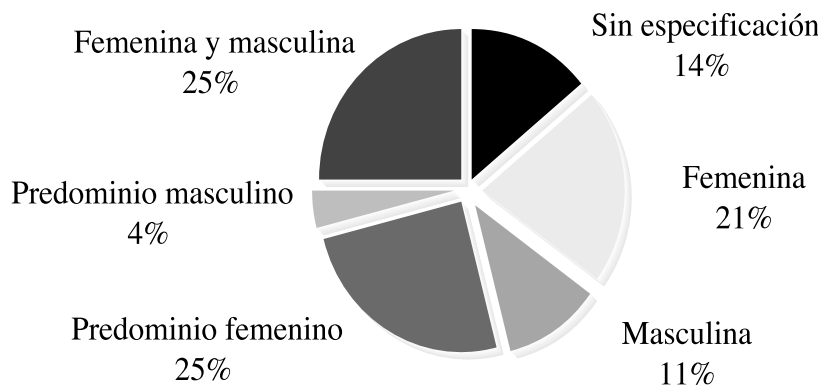

Base: 28 (No. de investigaciones analizadas dentro del abordaje socio-cultural, de naturaleza empírica y con fuente primaria compuesta por personas ${ }^{14}$ )

sias sobre el encuadramiento de la etnografía como técnica, se resolvió asumirla como tal, incluyendo las investigaciones que siguieron esa orientación en la categoría combinación de técnicas.

${ }^{14}$ La base de esta clasificación (28) está compuesta por los estudios empíricos de recepción que se valieron de muestras de información/persona, permaneciendo el porcentaje de investigaciones que no especificaron sus muestras en 


\section{GRÁFICO 10 \\ TÉCNICAS DE OBSERVACIÓN}

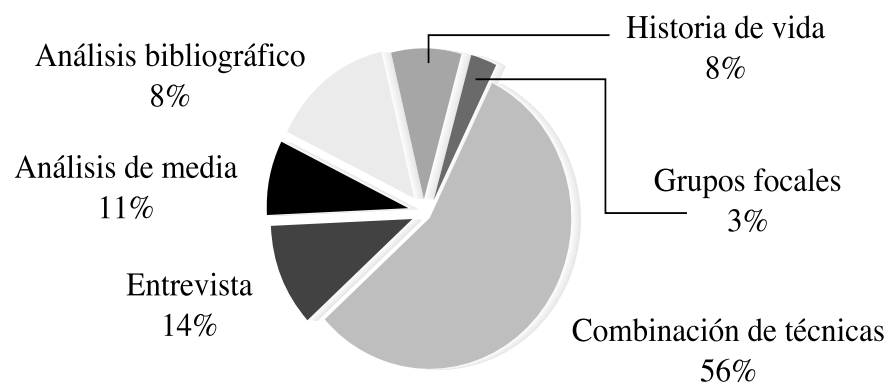

Base: 36 (No. de investigaciones analizadas dentro del abordaje socio-cultural)

grupos focales, el análisis de los media (cuando el soporte son documentos provenientes de los media, por ejemplo, capítulos de telenovela, ejemplares de diario, programas radiofónicos) y el análisis bibliográfico (cuando el documento se refiere a obras).

Se considera metodología el diseño global de la investigación que relaciona los métodos utilizados en la colecta y análisis de los datos. En realidad, debería también justificar la selección e interpretación de los datos con referencia a los marcos adoptados (Jensen, 1993:14). Esta clasificación propone identificar las investigaciones de carácter cualitativo, cuantitativo y aquéllas que presentan una estrategia combinada (cuali/ cuanti) (Gráfico 11).

\section{CONCLUSIÓN}

Se puede decir que, hasta el momento, entre los principales resultados obtenidos está la idea de que la tematización de la recepción, su debate entre los investigadores del área y divulgación en el medio académico, en Brasil, todavía es débil si es comparada con la producción de investigación, presencia del tema en los periódicos especializados y congresos,

\footnotetext{
la descripción metodológica. Está excluida de esta base una investigación que trabajó con la totalidad de su universo de investigación.
} 


\section{GRÁFICO 11 \\ METODOLOGÍA ADOPTADA}

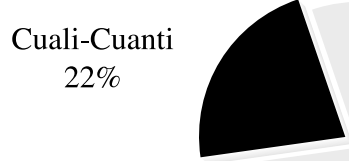

Cuantitativa

Cualitativa

$78 \%$

$0 \%$

Base: 36 (No. de investigaciones analizadas dentro del abordaje socio-cultural)

por ejemplo, en el medio académico británico o incluso el estadounidense. Entretanto, en Brasil, el desarrollo de la década de los noventa fue revelando un crecimiento de la investigación académica en esa área.

Es principalmente en el ámbito de la investigación de las culturas populares donde, a partir de mediados de 1980, empezaron a ser desarrollados los estudios de recepción mediática en América Latina. Diferentes abordajes de la recepción se encuentran en discusión en el contexto latino-americano, pero nuestro interés recae especialmente en aquellos estudios que son influenciados por la perspectiva de las mediaciones, propuesta por Jesús Martín-Barbero, y es viabilizada metodológicamente a través del modelo propuesto por Guillermo Orozco Gómez. En Brasil, la entrada y diseminación de ese referencial teórico-metodológico demoró un poco más.

Los estudios de recepción configuran, hasta el momento, el principal punto de desarrollo de los Estudios Culturales latinoamericanos; esto es, la problemática empírica que más ha contribuido para la constitución de ese campo de estudios en América Latina. La problemática de la recepción, tratada a la luz de las contribuciones de los Estudios Culturales, está vinculada a un cuadro amplio de relaciones sociales y culturales, esto es, abarca el estudio de diferentes mediaciones sociales y culturales que están más allá de la exposición inmediata y uso de los media. 
Sin embargo, a diferencia de lo que ocurrió en el contexto anglosajón, los estudios de recepción latinoamericanos no se constituyeron a través del pasaje de análisis basados estrictamente en los textos para un enfoque más contextualista. En América Latina, la investigación en comunicación de los años setenta y parte de los ochenta difundía una concepción reproductivista de la cultura. La adopción de un concepto de ideología y dominación no propició el ambiente para el florecimiento de una visión menos maniqueísta sobre los textos populares, o sea, los contenidos de las industrias culturales.

En el mismo período, en el contexto brasileño, el embrión del enfoque que más tarde desembocaría en la recepción fue constituido por estudios de carácter teórico y metodológico variado, muchos de ellos realizados fuera del campo académico de la comunicación. A partir de la década de los ochenta se acentúa la producción de investigaciones de recepción, surgiendo investigaciones como la de Leal (1986) y Lins y Silva (1986), que expresan una articulación de la recepción con el ámbito más amplio de la cultura. Dichas investigaciones señalan una busqueda de alternativas teóricas diferenciadas, revelando proximidades con los Estudios Culturales, mismas que no han sido formalizadas.

Fue fundamentalmente a través de la publicación y diseminación de las ideas de Martín-Barbero, propuestas en De los medios a las mediaciones (1987), como los estudios de recepción latinoamericanos desarrollaron una perspectiva donde están envueltas distintas mediaciones sociales y culturales que vinculan la recepción mediática con las relaciones con la vida social. De ese modo, la temática de la recepción se vincula, pero no se limita a la relación con los media, construyendo una posición mucho más contextualista. Sin embargo, en Brasil, hasta la segunda mitad de los años ochenta, es casi inexistente la presencia de la reflexión barberiana en la fecundación de los estudios de recepción, dada la dificultad de circulación de esos textos. ${ }^{15}$

Influenciados, sobre todo por la obra seminal de Martín-Barbero (1987), los estudios de recepción realizados a partir del final de la déca-

$\overline{15}$ Creemos que la precaria red de periódicos especializados, así como la dificultad de los mismos para mantener su periodicidad y la utilización de la lengua española, de cierta forma contribuyó para retardar el diálogo entre la producción nacional y la reflexión latinoamericana en lengua española. 
da de los ochenta, en el territorio latinoamericano de lengua española, descubrían y celebraban un sujeto-receptor que resignificaba los mensajes mediáticos, identificando sus negociaciones y resistencias a la lógica de los medios.

No obstante, en el territorio brasileño es sólo en la década de los noventa cuando van a ocurrir cambios importantes en relación con esa temática. Por ejemplo, en 1990 surge, de forma organizada, el primer foro de debates que va a reunir investigadores interesados en el tema de la recepción. ${ }^{16}$ Luego, en 1992, surge más un grupo de discusiones, llamado de "Televisão e Audiência", ${ }_{17}$ dentro de la Associação dos Programas de Pós-Graduação em Comunicação (COMPÓs). Hasta ese momento, la investigación de recepción era desarrollada de forma dispersa y esporádica, en distintos programas de posgrado (sociología, antropología, educación y comunicación) y, sobre todo, individualmente.

Está claro que esa dispersión todavía existe y es saludable en la medida en que concurren para enriquecer el análisis de la problemática a través de principios anclados en diferentes áreas del conocimiento.

Esos espacios de debate, así como la consolidación de algunos programas de posgrado en comunicación (principalmente, la Escola de Comunicações e Artes/Universidade de São Paulo y la Universidade Metodista de São Paulo-São Bernardo do Campo (SP), que aglutinan investigadores interesados en la divulgación del pensamiento comunicacional latinoamericano) propiciaron la circulación de textos y de las ideas de algunos autores que, más tarde, van a ser identificados como los propulsores de los Estudios Culturales latinoamericanos. Entre esos autores se destaca el papel de Jesús Martín-Barbero y Néstor García Canclini.

Por otro lado, como el propio título de la investigación lo indica, nuestro interés incide en la forma como la noción de género fue y está siendo incorporada por los estudios de recepción, pues la investigación empírica se fundamenta muchas veces exclusivamente en los relatos de mujeres. Aunque nuestra investigación está todavía en proceso, las evi-

${ }^{16}$ La Sociedad Brasileña de Estudios Interdisciplinares de la Comunicación (INTERCOM) que reúne investigadores, a nivel nacional, creó el "Grupo de Trabalho Comunicação y Recepção”, en 1990. No obstante, éste fue extinto en 2000.

17 En 1996, el grupo de trabajo asumió la denominación de "Mídia e Recepção". 
dencias recolectadas hasta esta etapa revelan que la categoría de género está siendo usada para indicar apenas una distinción sexual entre femenino y masculino. En algunos casos, la misma categoría puede hasta ser asociada a papeles sociales -por ejemplo, madre y dueña de casa-, pero esas actuaciones específicas no contribuyen para explicar, por lo menos parcialmente, determinados procesos sociales y sus resultados objetivos.

Al utilizar la categoría de género como solamente una diferenciación biológica, los estudios de recepción corren el riesgo de adherirse a un discurso esencialista sobre el género. Así, si género es equivalente a sexo y éste dice respecto a las diferencias anatómicas entre macho y hembra, no hay razón para reflexionar sobre esa categoría. Por ello, la incorporación de la categoría de género no ha significado un cambio de paradigma analítico como tal vez era esperado por una perspectiva feminista, o sea, pensarlo fundamentalmente como una construcción social e histórica producida sobre características biológicas.

Si a partir de mediados de los años ochenta se observaba en América Latina un cambio en dirección a la audiencia, hoy se constata un cúmulo de investigaciones que se detienen en el estudio de una audiencia compuesta, en muchos casos, por mujeres. El hecho de privilegiar como objeto de estudio a la telenovela y como ambiente de investigación el espacio doméstico y la familia contribuyó para ese direccionamiento.

Ese conjunto de investigaciones está señalando la necesidad de problematizar el significado de las categorías mujer y género empleadas, pues se observa que prácticamente no existe una discusión de las relaciones de género en los estudios culturales latinoamericanos, específicamente cuando están en foco los estudios de recepción. Luego, es necesario decir que no hay una articulación entre estudios feministas y estudios de recepción realizados en América Latina y, en especial, en Brasil.

\section{BIBLIOGRAFÍA}

ABRAMO, Perseu ( 1979) "Pesquisa em ciências sociais" en Sedi Hirano (Org.) Pesquisa social-Projeto e planejamento, São Paulo: T. A. Queiroz Editor.

Booth, W. C., Colomb, G. G. E Williams, J. M. (2000) A arte da pesquisa. São Paulo: Martins Fontes.

ESCOSTEGUY, Ana Carolina (2001) "Os Estudos Culturais e sua vertente latinoamericana" en Tendências da Comunicação, No. 4, Porto Alegre: LP\&M e RBS. 
EscosteguY, Ana Carolina (2002) "Os estudos de recepção e as relações de gênero: algumas anotações provisórias” en Ciberlegenda, http://www.uff.br/ mestcii, No. 7.

GODOY, Arilda Schmidt (1995) "Introdução à pesquisa qualitativa e suas possibilidades” en Revista Administração de Empresas, São Paulo, Vol. 35, No. 2, pp. 57-63.

- (1995) "Pesquisa qualitativa-Tipos fundamentais" en Revista Administração de Empresas, São Paulo, Vol. 35, No. 3, pp. 20-29.

Grupo de Estudos sobre Práticas de Recepção a Produtos Mediáticos (1998) "O tema da recepção mediática na bibliografia naciona, uma aproximação inicial”, Revista Novos Olhares,No. 2, ECA/USP, pp. 50-55.

JACKS, Nilda (1999) “A pesquisa de recepção no Brasil: em busca da influência latino-americana" en Lopes, Maria Immacolata (Org.) Vinte anos de ciências da comunicação no Brasil-Avaliação e perspectivas. São Paulo: Intercom/ Unisanta, pp. 171-183.

- et al. (2002) Estudos brasileiros de recepção: a produção acadêmica da década de 90. Porto Alegre: Editora da Universidade.

JENSEN, K. B. e Jankowski, N. W. (Orgs.) (1993) Metodologías cualitativas de investigación en comunicación de masas. Barcelona: Ediciones Bosch.

LEAL, Ondina Fachel (1986) A leitura social da novela das oito, Petrópolis:Ed. Vozes.

LINS da Silva, Carlos Eduardo (1985) Muito além do Jardim Botânico. São Paulo: Summus.

LOPES, Maria Immacolata V. de (1990) Pesquisa em comunicação-Formulação de um modelo metodológico. São Paulo: Edições Loyola.

- (1993) "Estratégias metodológicas de recepção", Revista Brasileira de Comunicação/Intercom, Vol.XVI, No. 2, pp. 78-86.

- (1995) "Recepção dos meios, classes, poder e estrutura", Comunicação $e$ Sociedade, Núm. 23, pp. 99-110.

QUEIROZ, Maria Isaura Pereira de (1991) Variações sobre a técnica de gravador no registro da informação viva. São Paulo: T. A. Queiroz Editor. 